\title{
El debido proceso en el ejercicio de la potestad sancionatoria de la administración, en materia de transporte terrestre
}

\section{The right to due process in the sanctions imposed by the state in land transport}

Recibido : 22/04/13

Aprobado : 15/08/2013

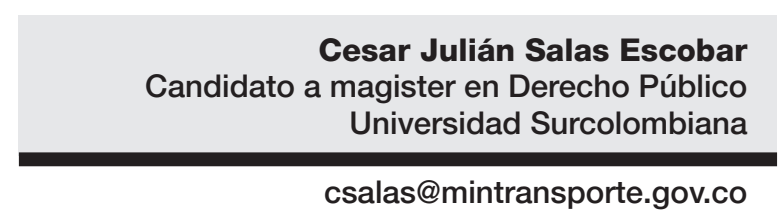

«El debido proceso es aquel razonablemente estructurado para averiguar la verdad, de formas consistentes con las otras finalidades del ordenamiento jurídico, en cuanto a determinar si se ha dado alguna violación legal y en qué circunstancias» Jhon Rawls

\section{RESUMEN}

En Colombia el sector del transporte terrestre automotor ha crecido exponencialmente a tal magnitud que tanto la estructura, la actividad y las ganancias generadas han tenido que ser objeto de estudio e intervención por parte del Estado, al punto de elevar tal servicio a la categoría de público esencial, en aras de conciliar los intereses generales y privados en juego.

La situación fáctica reseñada en el párrafo anterior, ha permitido que el Estado refuerce de forma vigorosa su intervención a través de la potestad sancionatoria de la administración, que no es otra cosa que una función de control estatal mediante la cual el Estado sanciona aquellas conductas que atentan contra los cometidos estatales propugnados por la Constitución Política de 1991 y las leyes que desarrollan y regulan el servicio público esencial del transporte terrestre automotor. Sin embargo, el ejercicio de esta potestad sancionatoria encuentra como contrapeso el respeto al debido proceso de los investigados y sancionados, lo que obliga al Estado a respetar unos procedimientos, principios y contenidos que en forma de límites permiten que sus decisiones sean ajustadas a derecho.

Pese a la aparente claridad conceptual reseñada, existe un importante vacío doctrinal y desarrollo unificado sobre el tema, que ha llevado por la vía jurisprudencial a que la Corte Constitucional Colombiana, en adelante la Corte, y el Consejo de Estado Colombiano, en adelante el Consejo, Iogren una caracterización que merece una esquematización y desarrollo por parte de la doctrina y estudiosos del derecho, en especial de los conceptos recogidos en los fallos proferidos durante los últimos 15 años.

\section{PALABRAS CLAVE}

Transporte terrestre automotor, potestad sancionatoria de la administración, derecho al debido proceso, servicio público de transporte.

\section{ABSTRACT}

In Colombia, the land transport sector has grown exponentially, to extent that both the structure, activity and the profits had to be studied and regulated by the State, in order to balance public and private interests at stake. 
The factual situation outlined in the previous paragraph has allowed the state to vigorously strengthen its intervention through the punitive power of the administration, which is nothing more than an instrument through which the state punishes behaviors that violate the committed state advocated by the 1991 Constitution and the laws that develop and regulate the public land transport service. However, the practice of this power to punish is to counterbalance respect for due process of the investigated and punished, which obliges the state to respect procedures and principles for its decisions in accordance with law.

Despite, the apparent conceptual clarity outlined, there is a gap unified doctrinal development on the subject, which has led to their unification and development through to case law by the Constitutional Court, in the Court below, and the Colombian State Council, in forward the Council, who through their criteria have been deserving characterization and development by outlining the doctrine and legal scholars, especially the concepts embodied in the judgments uttered during the last 15 years.

\section{KEYWORDS}

Automotive Land Transportation, administration sanctioning authority, right to due process, public transport service..

\section{INTRODUCCIÓN}

Conforme a la normatividad vigente ${ }^{1}$ en derecho colombiano, la administración pública podrá ejercer la potestad sancionatoria como función de control en materia de transporte terrestre automotor a través de un procedimiento con jurisdicción y competencia funcional ${ }^{2}$ que será llevado a cabo por los alcaldes y la Superintendencia de Puertos y Transporte, imponiendo sanciones que van desde las amonestaciones, las multas, hasta la suspensión 0 cancelación de la licencia, registros, habilitaciones o permisos de operación de las empresas de transporte. Teniendo en cuenta la importancia capital del transporte terrestre automotor como un servicio que potencia el desarrollo social y económico de un país, este artículo pretende dilucidar bajo que límites constitucionales el Estado Colombiano puede ejercer la potestad sancionatoria administrativa en contra de los operadores de dicho servicio cuando estos infrinjan la normatividad y los principios que regulan el transporte como un servicio público inherente a la finalidad Social del Estado.
Así, el documento inicia analizando cuales han sido los criterios jurisprudenciales que la Corte y el Consejo han realizado en aras de determinar la naturaleza y definición tanto del transporte terrestre automotor como de la potestad sancionatoria que el Estado aplica a este. Posteriormente, se caracterizarán los parámetros que la Corte y el Consejo han fijado con la intención de defender el derecho al debido proceso cuando este es violado por parte de las autoridades administrativas en ejercicio de la potestad sancionatoria, y por último, se reseñan casos específicos en que la Corte y el Consejo han resuelto articulando el debido proceso como límite en el sector del transporte terrestre automotor.

Con todo lo anterior, el presente artículo concluye que la función estatal de control de tipo sancionatorio administrativo por parte de las autoridades públicas en el sector del transporte terrestre automotor no se ejerce de modo arbitrario y omnímodo y que por el contrario, está sujeto a la regulación de los principios básicos que la Constitución Política de

1 El Procedimiento sancionatorio en materia de transporte terrestre automotor está regulado por la Ley 105 de 30 de diciembre de 1993 "Por la cual se dictan disposiciones básicas sobre el transporte, se redistribuyen competencias y recursos entre la Nación y las Entidades Territoriales, se reglamenta la planeación en el sector transporte y se dictan otras disposiciones" y por la Ley 336 de 20 de diciembre de 1996 "Estatuto general de transporte".

2 Hacemos referencia al concepto de lo funcional en materia de jurisdicción y competencia sobre el transporte terrestre automotor, en la medida que dicha jurisdicción y competencia recae sobre el encargado de ejercer la potestad sancionatoria conforme a las funciones y competencia legalmente asignadas. 
1991 establece a favor de los administrados y procesados, en especial los límites que impone el respeto al derecho constitucional fundamental del debido proceso regulado en el artículo 29 de la misma carta política, que a manera de mandatos, establecen claros criterios y comportamientos que no deben ser rebasados por parte de las autoridades públicas.

\section{DEFINICIÓN Y NATURALEZA DEL TRANSPORTE TERRESTRE AUTOMOTOR Y DE LA POTESTAD SANCIONATORIA DE LA ADMINISTRACIÓN EN MATERIA DE TRANSPORTE}

\subsection{El concepto transporte terrestre automotor}

Es un error frecuente dentro de los estudios y aproximaciones del transporte terrestre automotor, asemejarlo 0 identificarlo con el concepto de tránsito terrestre automotor. Con el fin de evitar tales imprecisiones conceptuales, la ley colombiana define al transporte terrestre automotor como aquella actividad de tipo transportador que en su conjunto organizado de operaciones propende por la ejecución del traslado de personas o cosas, bien sea de forma separada 0 de forma conjunta de un lugar a otro bajo la regulación y autorización que fija el ordenamiento jurídico colombiano. ${ }^{3}$ Por su parte, el tránsito terrestre automotor es aquella actividad que regula la circulación de los agentes que componen la movilidad, por lo tanto su objeto de normativización recae sobre peatones, usuarios, pasajeros, conductores, motociclistas, ciclistas, agentes de tránsito, y vehículos por las vías públicas o privadas que están abiertas al público, 0 en las vías privadas donde internamente circulen vehículos; así como la actuación y procedimientos de las autoridades de tránsito, lo cual, al igual que en el transporte terrestre automotor, está bajo la regulación, control y vigilancia del ordenamiento jurídico colombiano. ${ }^{4}$

Una vez esbozada la anterior distinción conceptual, la presente reflexión crítica girará únicamente en torno al concepto de transporte terrestre automotor, y especialmente a la influencia del debido proceso como límite en la función estatal de control de tipo sancionatorio administrativo cuando por razones totalmente regladas el Estado Colombiano sanciona a aquellos agentes que por su actividad participan del conjunto organizado de operaciones que propende por la ejecución del traslado de personas o cosas, en el caso de infringir la normatividad obligada a cumplir.

Consecuentes con el planteamiento descrito, se nos presenta la caracterización de la naturaleza del transporte terrestre automotor como una tarea a realizar, teniendo en cuenta que auscultar tal naturaleza es imprescindible para analizar qué poder tiene el Estado sobre aquella actividad. Así, el transporte terrestre automotor ha sido catalogado como un servicio público de carácter esencial, ${ }^{5} \mathrm{y}$ que por lo tanto está bajo especial protección del Estado. ${ }^{6}$ Sin embargo, la prestación del servicio como tal puede estar encomendada a los particulares. ${ }^{7}$

3 La Ley 136 de 20 de diciembre de 1996 "estatuto general de transporte" en su artículo 6 prescribe que "por actividad transportadora se entiende un conjunto organizado de operaciones tendientes a ejecutar el traslado de personas o cosas, separada o conjuntamente, de un lugar a otro, utilizando uno o varios modos, de conformidad con las autorizaciones expedidas por las autoridades competentes basadas en los Reglamentos del Gobierno Nacional".

4 La Ley 769 del 6 de julio de 2002 "Por la cual se expide el Código Nacional de Tránsito Terrestre y se dictan otras disposiciones" en su artículo 1 dice que "las normas del presente Código rigen en todo el territorio nacional y regulan la circulación de los peatones, usuarios, pasajeros, conductores, motociclistas, ciclistas, agentes de tránsito, y vehículos por las vías públicas o privadas que están abiertas al público, o en las vías privadas, que internamente circulen vehículos; así como la actuación y procedimientos de las autoridades de tránsito".

5 El artículo 5 de la Ley 136 de 20 de diciembre de 1996 establece que "el carácter de servicio público esencial bajo la regulación del Estado que la ley le otorga a la operación de las empresas de transporte público, implicará la prelación del interés general sobre el particular, especialmente en cuanto a la garantía de la prestación del servicio y a la protección de los usuarios, conforme a los derechos y obligaciones que señale el Reglamento para cada Modo".

6 El artículo 4 de la Ley 136 de 20 de diciembre de 1996 establece que "el transporte gozará de la especial protección estatal y estará sometido a las condiciones y beneficios establecidos por las disposiciones reguladoras de la materia, las que se incluirán en el Plan Nacional de Desarrollo...”.

7 La habilitación a los particulares para la prestación de servicios públicos esta incardinada en el inciso 2 del artículo 365 de la Constitución Política de 1991, en este, se manifiesta que "los servicios públicos estarán sometidos al régimen jurídico que fije la ley, 
Es de resaltar que la jurisprudencia de la Corte y el Consejo han sido congruentes con la posición fijada por el legislador, acerca de la naturaleza de servicio público de carácter esencial que ostenta el transporte terrestre automotor. Así, la Corte ha considerado que el transporte terrestre automotor es un servicio público, y que por lo tanto, en su prestación y desarrollo está implicado el interés general sobre el particular, ${ }^{8}$ y que al ser un servicio de esta índole, el mismo es inherente a la finalidad social del Estado. ${ }^{9}$

\subsection{La potestad sancionatoria de la administración en materia de transporte}

Para ubicar y definir la potestad sancionatoria de la administración en materia de transporte terrestre automotor, se debe partir de la idea anteriormente reseñada de que el transporte terrestre automotor es un servicio público de carácter esencial. Esta caracterización de servicio público pone de presentes unas connotaciones de orden estatal, donde por orden de la misma Constitución de 1991, ante el evento de que una determinada actividad sea catalogada como servicio público, será deber del Estado su vigilancia, su control y su regulación. ${ }^{10}$
Estos tres ejercicios de función estatal sobre la prestación de servicios públicos, son verdaderos poderes que el Estado se abroga en aras de asegurar que la prestación de aquellos sea consecuente con las finalidades y cometidos estatales, y que además se presten de tal modo que lleguen de forma eficiente a todos los habitantes del territorio Colombiano, ${ }^{11}$ todo esto en consonancia con la ya anotada premisa de que en esta materia deberá prevalecer el interés general sobre el particular.

De los tres poderes reservados al Estado en materia de servicios públicos, destaca el poder de control, que es definido como aquella función estatal de policía administrativa que busca garantizar la eficiencia en la gestión, el ejercicio de las actividades dentro del marco de la libre y leal competencia, y la protección de los usuarios (Atehortúa, C. 2006: 246).

Al catalogar al transporte terrestre automotor como un servicio público de carácter esencial, el Estado queda legitimado para determinar vía preventiva y sancionatoria los controles y lineamientos mediante los cuales los particulares podrán prestar dicho servicio en el territorio colombiano, dándole a su vez a este último una herramienta de carácter sancionatorio ${ }^{12}$ que permita promover el

podrán ser prestados por el Estado, directa o indirectamente, por comunidades organizadas, o por particulares". En consonancia con el artículo constitucional citado, el apartado final del artículo 4 de la Ley 136 de 20 de diciembre de 1996 permite que la prestación del transporte terrestre automotor pueda estar encomendado a los particulares.

8 Es de resaltar que tanto la jurisprudencia de la Corte como la Ley 136 de 20 de diciembre de 1996, son enfáticas en afirmar que en el desarrollo del transporte terrestre automotor prima el interés general sobre el particular. Referente importante de esta premisa lo constituye el artículo 5 de la Ley 136 de 1996 cuando manifiesta que "el carácter de servicio público esencial bajo la regulación del Estado que la ley le otorga a la operación de las empresas de transporte público, implicará la prelación del interés general sobre el particular, especialmente en cuanto a la garantía de la prestación del servicio y a la protección de los usuarios, conforme a los derechos y obligaciones que señale el Reglamento para cada Modo". Negrita realizada por el autor del presente trabajo.

9 En una sentencia de tutela al calificar al transporte terrestre automotor como un servicio público, la Corte dijo que al ser servicio público es "inherente a la finalidad social del Estado. Es deber del Estado asegurar su prestación eficiente a todos los habitantes del territorio nacional". CConst, T-199/2006, C. Gaviria. Por su parte, el Consejo determinó que "el transporte público implica la prelación del interés general sobre el particular, en especial para garantizar su prestación eficiente y la protección de los usuarios. Para la prestación de este servicio las empresas, formas asociativas de transporte y de economía solidaria deben estar habilitadas por el Estado y acreditar las condiciones que demuestren capacidad técnica, operativa, financiera, de seguridad y procedencia del capital aportado". CE, 10 May.2007. M, Ortiz.

10 El inciso 2 del artículo 365 de la Constitución Política de 1991 si bien permite que los servicios públicos puedan ser prestados por el Estado, directa o indirectamente, por comunidades organizadas o por los particulares; también reserva al Estado de forma exclusiva la regulación, el control y la vigilancia de dichos servicios.

11 El inciso 1 del artículo 365 de la Constitución Política de 1991 prescribe que "los servicios públicos son inherentes a la finalidad social del Estado. Es deber del Estado asegurar su prestación eficiente a todos los habitantes del territorio nacional”.

12 El carácter sancionatorio de la potestad administrativa parte de la existencia de esta junto a la potestad penal de los Tribunales, como un ius puniendi superior del Estado, que además es único, de tal manera que aquéllas no son sino simples manifestaciones concretas de éste. Según la posición de Nieto (2005), el Derecho público estatal proporciona al Derecho administrativo sancionador un soporte conceptual y operativo del que antes carecía. La consecuencia de este planteamiento ha sido el establecimiento de un 
cumplimiento de las normas impuestas en caso de su transgresión. ${ }^{13}$

Concomitante al interés legal y jurisprudencial de caracterizar el transporte terrestre automotor, tanto la Corte como el Consejo se han preocupado por destacar la naturaleza de la potestad sancionatoria de la administración, en aras de garantizar el apego a la legalidad tanto de los operadores del servicio de transporte terrestre automotor, como de las autoridades encargadas de controlarlo. ${ }^{14}$

A nivel doctrinal se ha identificado la facultad de la administración para imponer sanciones como una función estatal que conlleva una prerrogativa de mando que tiene como cometido reprimir las acciones u omisiones antijurídicas para poder asegurar el cumplimiento de las decisiones de la administración. ${ }^{15}$ Sobre este particular, la Corte ha reconocido en sus fallos la facultad del Estado para utilizar la potestad sancionatoria de carácter administrativo, así la Corte en sentencia determinó:

Resulta evidente que la violación por parte de los particulares de las normas que reglamentan una actividad peligrosa como es el transporte público de pasajeros, lo cual implica asumir las consecuencias que las autoridades de tránsito establezcan en el ejercicio de sus atribuciones de inspección, vigilancia y control de transporte público de pasajeros, pues las operadores de transporte deben someterse al imperio de las leyes y adecuarse a los trámites regulados para el efecto. (CConst, T- 976/1999, F. Morón)

Analizando lo reseñado en el párrafo anterior, es posible observar y concluir cómo desde una primera etapa, la Corte entiende que los operadores del servicio de transporte terrestre automotor también están implicados en la observancia y aseguramiento de los cometidos estatales, y que por esta razón se ven sometidos a la observancia de las normas que permiten articular la iniciativa privada con los intereses públicos que el transporte conlleva, y que en caso de transgredir este equilibrio, dichos operadores se verían avocados a una serie de sanciones impuestas a través de la potestad sancionatoria ejercida por parte de autoridades públicas de carácter administrativo. ${ }^{16}$

En complemento de los criterios anteriormente destacados, se ha especificado por parte de la Corte que la naturaleza de la potestad sancionatoria de la administración en el ámbito del transporte terrestre automotor, haproscrito toda forma de responsabilidad objetiva, haciendo que la responsabilidad que debe

sistema represivo singularmente completo y armonioso, superador de viejas contradicciones y capaz de resolver por sí mismo las dificultades teóricas y prácticas que todavía existen o que pueden ir surgiendo (pp. 25 - 26). Esta diferenciación entre el derecho penal del Estado y el derecho administrativo sancionador, ha permitido especialmente en la doctrina española una nutrida relación entre ambos campos del Derecho. Así, De La Rosa Cortina (2003) entiende que el principio Non Bis In Idem y otros principios y garantías del derecho penal, deben también ser aplicables al derecho administrativo sancionador (pp. 92 - 95). De la misma opinión de la necesidad de una regulación y estructura como la que tiene el derecho penal pero enfocado hacía el derecho administrativo sancionador es Benlloch (1998).

13 Esta potestad sancionatoria en cabeza de la administración ha sido reconocida en diversos ordenamientos jurídicos, así lo pone de manifiesto Parada Vásquez (1972). en los ordenamientos jurídicos de Francia, Italia, Inglaterra y España.

14 En los más de 20 fallos encontrados en la recolección de datos del presente artículo, se evidenció que tanto el Consejo como la Corte tienen una misma claridad conceptual que entiende que la potestad sancionatoria de la administración en el transporte terrestre automotor es un poder que permite corregir los desvíos de los operadores del servicio, y hace cumplir las finalidades del Estado. Pero que además debe estar sometida al imperio de la Ley y por ende reglada, de tal manera que permita asegurar a quien está siendo objeto de dicha facultad, la protección de sus derechos constitucionales fundamentales, entre ellos el debido proceso. 15 El autor Ossa Arbeláez (2009) entiende que la facultad de sancionar es un instrumento que garantiza el interés general y constituye un mecanismo de protección del Estado, para cumplir sus fines, en cuanto que preserva el orden jurídico institucional. Manifiesta que la potestad sancionatoria es un complemento de la facultad de mando en cuanto asegura el cumplimiento de decisiones administrativas.

16 También el Consejo ha dado el mismo trato que la Corte a la facultad sancionatoria de la administración sobre el transporte terrestre automotor, con base en la finalidad de hacer cumplir los cometidos estatales, Así, en un célebre fallo el Consejo sostuvo "la Administración tiene las facultades de introducir las modificaciones que considere necesarias para obtener una mejor organización y funcionamiento del servicio, exigir al operador del servicio la adaptación del mismo a las nuevas demandas o conveniencias para los usuarios, la vigilancia y control sobre la actividad desarrollada, lo cual se justifica por el interés público que aquella involucra, y el derecho a revocar la licencia de funcionamiento antes de cumplirse el plazo estipulado por razones de interés público o por circunstancias previamente definidas en la Constitución, la ley o los reglamentos". CE, 10 May. 2007, M, Ortiz. 
endilgar la administración deba ser plenamente demostrada. ${ }^{17}$ Además, resulta importante destacar cómo la Corte enfatiza en la importancia del debido proceso administrativo desde la óptica constitucional tratándose de la facultad sancionadora. ${ }^{18}$ Igualmente reconoce en el legislador una amplia facultad para regular el transporte terrestre automotor, permitiéndole abarcar tanto la función preventiva como la sancionadora. ${ }^{19}$

Esta potestad sancionatoria de la administración de la cual se ha hecho referencia en los párrafos precedentes, tiene una regulación en dos textos normativos: las leyes 105 de 30 de diciembre de 1993 y 336 de 20 de diciembre de 1996. Conforme a estos textos, la administración pública podrá ejercer la potestad sancionatoria como función de control en materia de transporte terrestre automotor a través de un procedimiento con jurisdicción y competencia funcional que será llevado a cabo por los alcaldes y la Superintendencia de Puertos y Transporte, pudiendo imponer a los operadores y empresas de transporte sanciones $^{20}$ que van desde las amonestaciones, las multas, hasta la suspensión o cancelación de la licencia, registros, habilitaciones o permisos de operación y la retención 0 inmovilización de vehículos. Estas sanciones serán aplicadas mediante procedimiento escrito conforme al tipo de transporte terrestre automotor de que se trate, que comprende el transporte intermunicipal, el transporte de carga, el transporte especial de pasajeros, el transporte mixto municipal, el transporte individual público y el transporte vehicular colectivo.

17 En una sentencia de constitucionalidad, donde los demandantes argumentaban que la norma objeto de inconstitucionalidad castigaba bajo la modalidad de responsabilidad objetiva al propietario del vehículo con el pago de la multa al prescribir que: "no obstante lo anterior, las autoridades competentes podrán contratar el servicio de medios técnicos y tecnológicos que permitan evidenciar la comisión de infracciones o contravenciones, el vehículo, la fecha, el lugar y la hora. En tal caso se enviará por correo dentro de los tres (3) días hábiles siguientes la infracción y sus soportes al propietario, quien estará obligado al pago de la multa".

La Corte determinó que la norma en comento que "no establece una forma de responsabilidad objetiva ni viola el derecho al debido proceso, pues una interpretación sistemática y armónica de la misma, permite advertir que el propietario del vehículo está en capacidad de comparecer al proceso administrativo para ejercer la defensa de sus intereses, de manera que la obligación de pagar la multa solo se produce cuando se establezca su culpabilidad, es decir, cuando se pruebe que él fue quien cometió la infracción, o cuando éste lo admita expresa o implícitamente"

Cabe resaltar que en la mencionada sentencia la Corte fue enfática en señalar que "en todos los ámbitos del derecho sancionador, y en particular en el campo del derecho administrativo sancionatorio, está proscrita toda forma de responsabilidad objetiva, pues por esa vía se desconoce la garantía a la presunción de inocencia consagrada expresamente en el artículo 29 de la Carta Política, la cual se constituye en núcleo esencial del derecho al debido proceso, y cuyo significado se concreta en que nadie puede ser culpado de un hecho hasta tanto su responsabilidad no haya sido plenamente demostrada" (CConst, C- 980/2010, M.P. G. Mendoza)

18 En este orden de ideas, la Corte arguye que "cuando la Carta consagra el debido proceso administrativo, reconoce implícitamente la facultad que corresponde a la Administración para imponer sanciones, dentro de los claros límites constitucionales. En punto a este tema, la jurisprudencia constitucional ha expresado que la potestad sancionadora de la Administración: "(i) persigue la realización de los principios constitucionales que gobiernan la función pública, de conformidad con el artículo 209 de la Carta, esto es, igualdad, moralidad, eficacia, economía, celeridad, imparcialidad y publicidad, (ii) se diferencia de la potestad sancionadora por la vía judicial, (iii) se encuentra sujeta al control judicial, y (iv) debe cumplir con las garantías mínimas del debido proceso" (CConst, C- 089/2011, M.P. L.Vargas).

19 En la citada Sentencia de constitucionalidad la Corte precisó que "el Legislador tiene una amplia potestad tiene una amplia facultad de regulación en materia de tránsito terrestre, y que por tanto puede legítimamente imponer limitaciones, restricciones y sanciones a los usuarios del sistema de tránsito terrestre que cometan infracciones, siempre y cuando estas limitaciones y sanciones cumplan con una finalidad constitucional, sean razonables y proporcionales, y respeten el debido proceso. Así mismo, ha dejado sentado esta Corporación que en materia de procedimientos y procesos administrativos de tránsito, le asiste al Legislador una amplia potestad de regulación, con el respeto de todas las garantías que le son inherentes al derecho fundamental del debido proceso consagrado en el artículo 29 Superior". (CConst, C- 089/2011, M.P. L.Vargas).

20 El procedimiento sancionatorio administrativo llevado a cabo por las autoridades públicas de carácter administrativo en materia de transporte terrestre automotor contiene sanciones que se impondrán previamente establecida y demostrada la infracción por parte de la empresa y/o operador del servicio de transporte terrestre automotor de conformidad con la modalidad de transporte indicada, así el artículo 9 de la Ley 105 de 1993 establece que "Las autoridades que determinen las disposiciones legales impondrán sanciones por violación a las normas reguladoras del transporte, según las disposiciones especiales que rijan cada modo de transporte". Las diferentes sanciones que la autoridad público administrativa (alcaldes y Superintendencia de Transporte) puede imponer son: amonestación, multas, suspensión o cancelación de la licencia, registros, habilitaciones o permisos de operación y la retención o inmovilización de vehículos, su regulación y ponderación en cuanto a la cuantía está recogida en los artículos 44 al 52 de la Ley 336 de 1996. 
En conclusión, tanto la Corte como el Consejo han coincidido en la construcción de unos criterios que ven en el transporte terrestre automotor un servicio público de carácter esencial que al ser inherente a la finalidad social del Estado y demás cometidos estatales, se hace necesario no solo su regulación y vigilancia, sino también dotar al Estado de un control que permita corregir los desvíos que los operadores de dicho servicio puedan cometer, potestad calificada como de tipo sancionatorio, capaz de compeler al cumplimiento de los fines del Estado Social de Derecho, y permitir el equilibrio entre la propiedad privada y la función social que le es inherente, dicha potestad recae sobre autoridades públicas de orden administrativo del orden municipal y nacional, con capacidad de imponer una multiplicidad de sanciones conforme al modo de transporte terrestre de que se trate. Además dichos criterios jurisprudenciales han sido un desarrollo y complemento de los contenidos legislativos estudiados.

\section{IMPLICACIONES Y LÍMITES DEL DERECHO AL DEBIDO PROCESO EN LA POTESTAD SANCIONATORIA DE LA ADMINISTRACIÓN EN MATERIA DE TRANSPORTE TERRRESTRE AUTOMOTOR}

En el punto anterior, se logró caracterizar tanto el transporte terrestre automotor como la potestad sancionatoria de la administración en materia de transporte, se había a su vez anunciado someramente que esta tenía que ceñirse a unos límites y procedimientos que el mismo ordenamiento jurídico exige. Por todo esto, este acápite se dedicará a analizar cuáles son esos límites que tanto la Corte como el Consejo han establecido en cabeza de la administración, en aras de la defensa de los derechos constitucionales fundamentales de los administrados.

A pesar del grado de dispersión normativa sobre la potestad sancionatoria de la administración en materia de transporte terrestre automotor, se ha intentado definir y caracterizar tal poder como un verdadero derecho administrativo sancionador, con una potestad punitiva otorgada que se desarrolla dentro de un ordenamiento jurídico que exalte y brinde claridad en cuanto a sus normas procesales y procedimentales con las cuales se impone la sanción, en donde se encuentre tipificada la infracción, se señale la dosificación de la sanción y en general consagre un mínimo de garantías (Santofimio, J. 2003, 71-73). Llegar a este punto fue un trabajo que adelantó el Consejo, ${ }^{21}$ pero especialmente la Corte, ${ }^{22}$ vía jurisprudencial, ante las demandas de tutela como las acciones de inconstitucionalidad que los particulares promovían con ocasión de los desmanes de la administración en materia de imposición de sanciones y medidas en el sector del transporte terrestre automotor. ${ }^{23}$

21 Por su parte el Consejo deja entrever en sus decisiones el atacamiento de la potestad sancionatoria de la administración en el sector del transporte terrestre automotor a las leyes y principios que la Carta política establece, así, manifestó que "(I)as Leyes 105 de 1993, 336 de 1996, 769 de 2002, entre otras, han desarrollado las pautas constitucionales para que las autoridades locales dentro de sus respectivas jurisdicciones y de acuerdo con la ley, puedan expedir las normas y medidas necesarias para el mejor ordenamiento del tránsito de personas, animales y vehículos por las vías públicas, y la reglamentación del servicio de transporte público...La Administración tiene las facultades de introducir las modificaciones que considere necesarias para obtener una mejor organización y funcionamiento del servicio, exigir al operador del servicio la adaptación del mismo a las nuevas demandas o conveniencias para los usuarios, la vigilancia y control sobre la actividad desarrollada, lo cual se justifica por el interés público que aquella involucra, y el derecho a revocar la licencia de funcionamiento antes de cumplirse el plazo estipulado por razones de interés público o por circunstancias previamente definidas en la Constitución, la ley o los reglamentos”. CE, 10 May. 2007, M, Ortiz. Negrita del autor.

22 En un fallo la Corte manifiesta que "La administración debe ser estricta en la garantía del debido proceso en sus distintas actuaciones y debe procurar dar a conocer sus actos de la manera más efectiva posible, es decir, debe agotar todos los medios que estén a su alcance antes de proceder a la fijación de los edictos como mecanismo último para notificar”. CConst, T-214/2006, M. Monroy.

23 Ejemplo palpable del desconocimiento de la administración del debido proceso de los administrados en materia del ejercicio de la potestad sancionatoria en el transporte terrestre automotor, lo encontramos en los fundamentos fácticos de la sentencia de tutela T - 786 de 2000, donde la Dirección Regional de Cundinamarca del Ministerio de Transporte ordenó al gerente de una cooperativa de transporte la devolución de las tarjetas de operación de unos vehículos que no tenían la capacidad transportadora concedida, y ante la negativa de este por falta del consentimiento de los afectados, la Dirección procedió a realizar un operativo para retener dichas tarjetas, lo cual se realizó en una sola diligencia para luego ser devueltas y anuladas por el Ministerio. No 
En este intento de caracterizar la injerencia del debido proceso en la potestad sancionatoria de la administración en el sector de transporte terrestre automotor, la Corte ha realizado un esfuerzo ingente por tratar de definir cuáles son los tópicos del derecho constitucional al debido proceso contenido en el artículo 29 de la carta política, frente a la potestad punitiva de la administración. Así, la Corte Constitucional precisó que hacen parte de las garantías del debido proceso, el derecho a la jurisdicción, el derecho al juez natural, el derecho a la defensa, el derecho a un proceso público, el derecho a la independencia del juez y por último el derecho a la independencia e imparcialidad del juez 0 funcionario. Sobre estos componentes en particular, la Corte realizó las siguientes conceptualizaciones:

DERECHO A LA JURISDICCIÓN: "implica los derechos al libre e igualitario acceso ante los jueces y autoridades administrativas, a obtener decisiones motivadas, a impugnar las decisiones ante autoridades de jerarquía superior, y al cumplimiento de lo decidido en el fallo".

DERECHO AL JUEZ NATURAL: "identificado este con el funcionario que tiene la capacidad 0 aptitud legal para ejercer jurisdicción en determinado proceso 0 actuación de acuerdo con la naturaleza de los hechos, la calidad de las personas y la división del trabajo establecida por la Constitución y la ley".

DERECHO A LA DEFENSA: "entendido como el empleo de todos los medios legítimos y adecuados para ser oído y obtener una decisión favorable. De este derecho hacen parte, el derecho al tiempo y a los medios adecuados para la preparación de la defensa; los derechos a la asistencia de un abogado cuando se requiera, a la igualdad ante la ley procesal, el derecho a la buena fe y a la lealtad de todas las demás personas que intervienen en el proceso".

DERECHO A UN PROCESO PÚBLICO: "desarrollado dentro de un tiempo razonable, lo cual exige que el proceso o la actuación no se vea sometido a dilaciones injustificadas o inexplicables".

DERECHO A LA INDEPENDENCIA DEL JUEZ: "que solo tiene efectivo reconocimiento cuando los servidores públicos a los cuales confía la Constitución la tarea de administrar justicia, ejercen funciones separadas de aquellas atribuidas al ejecutivo y al legislativo".

DERECHO A LA INDEPENDENCIA E IMPARCIALIDAD DEL JUEZ O FUNCIONARIO: "quienes siempre deberán decidir con fundamento en los hechos, de acuerdo con los imperativos del orden jurídico, sin designios anticipados ni prevenciones, presiones o influencias ilícitas". (CConst, C-980/ 2010, G.Mendoza).

Como consecuencia de lo anterior, se resalta la importancia de los conceptos o componentes integrantes del derecho al debido proceso como límites a la potestad sancionatoria de la administración en materia de transporte terrestre automotor, pues los administrados y operadores del servicio siempre que sean objeto de una investigación y/o sanción, tendrán el derecho de exigir el respeto de estas garantías que la Corte ha establecido como de observatorio cumplimiento por parte de las autoridades públicas. ${ }^{24}$

A modo de conclusión, tanto el Consejo como la Corte, pero especialmente esta última, han destacado por limitar la potestad sancionatoria de la administración tratándose del transporte terrestre automotor, bajo la egida del respeto al constitucionalismo materializado en el derecho al debido proceso, derecho recogido

obstante esto, la Corte resalta que el Ministerio "desconoció entonces el derecho al debido proceso al haberse ordenado ilegítima e irregularmente la retención y anulación de las tarjetas de operación, cuando lo procedente era acudir a la jurisdicción de lo contencioso administrativo para anular el acto proferido por la administración y poder así emitir, posteriormente, uno ajustado a derecho". CConst, T-786/2000, A. Barrera. Este y muchos ejemplos fueron los encontrados en el presente artículo de reflexión crítica, donde se observa cómo la jurisprudencia de la Corte y el Consejo comienza a defender el respeto al debido proceso dentro de las actuaciones de orden sancionador, realizadas por la administración.

24 En definitiva la Corte a través de sus fallos ha reconocido que la potestad sancionatoria de la administración en materia de transporte terrestre automotor, esta reglada y que en cualquier caso debe respetar la normatividad constitucional y legal que protegen los derechos sustanciales y procesales de los administrados. Así, en un fallo determinó que el "derecho al debido proceso administrativo se vulnera por parte de las autoridades públicas, cuando estas no respetan las normas sustanciales y procedimentales previamente establecidas por las leyes y los reglamentos y con ello se vulnera de contera el derecho de acceso a la administración de justicia". CConst, C-089/2011, L. Vargas. 
en el artículo 29 de la Carta Política y que en palabras de la Corte, comprende las garantías de los administrados al derecho a la jurisdicción, al derecho a un juez natural, al derecho a la defensa, al derecho a un proceso público, al derecho a la independencia del juez y por último al derecho a la imparcialidad del juez o funcionario. Además, aduce que dichas garantías son de aplicación en los procedimientos sancionatorios de carácter administrativo que las autoridades adelanten en contra de los operadores del transporte terrestre automotor, y que por lo tanto las normas como las sanciones y procesos deben encaminarse a proteger y salvaguardar también los derechos constitucionales fundamentales de estos últimos.

\section{CASOS ESPECÍFICOS DE LIMITACIÓN DEL DEBIDO PROCESO SOBRE LA POTESTAD SANCIONATORIA DE LA ADMINISTRACIÓN EN MATERIA DE TRANSPORTE TERRESTRE AUTOMOTOR}

Una vez caracterizados los dos aspectos teóricos que la Corte y el Consejo han planteado en sus fallos como lo son la naturaleza y existencia de la potestad sancionatoria de la administración y su limitación por parte del derecho fundamental constitucional al debido proceso en el sector transporte terrestre automotor, nos propondremos a recapitular los ejemplos más paradigmáticos que sobre las normas y procesos sancionatorios en el sector ha establecido el ordenamiento jurídico colombiano, todo con la finalidad de concluir que las leyes y procesos en los casos indicados deben obedecer la legalidad y constitucionalidad que las sentencias reseñadas han trazado.

\subsection{Cambios en las autorizaciones de rutas, horarios, niveles de servicio y fijación de la capacidad transportadora}

En las sentencias analizadas se puede inferir que una zona de conflicto en la aplicación de la potestad sancionatoria de la administración en materia de transporte terrestre automotor, se da en los casos en que las autoridades públicas de forma unilateral realizan cambios en las autorizaciones de rutas, horarios, niveles de servicio y fijación de la capacidad transportadora de los operadores del servicio de transporte.

Sobre el particular, la Corte ha sido enfática en reiterar que ese tipo de procedimientos son una violación al debido proceso en virtud que la autorización de rutas, horarios, niveles de servicio y fijación de capacidad transportadora son actos administrativos de contenido particular, y que conforme al código contencioso administrativo, necesitan del permiso del particular directamente afectado para su revocatoria, y que en caso de proceder sin tal permiso y/o autorización la administración comete una flagrante violación al derecho al debido proceso del afectado. ${ }^{25}$

\subsection{Las notificaciones de comparendos por correo.}

Si bien el presente caso obedece a un tema de tránsito terrestre automotor y no de transporte terrestre automotor, su importancia radica en que el tema de notificaciones es extrapolable a los procedimientos sobre transporte terrestre automotor. Así, en sentencia C - 980 de 2010, mediante acción de inconstitucionalidad del

25 En refuerzo del concepto esgrimido, una empresa transportadora en calidad de demandante a través de acción de tutela demandó al Instituto Nacional de Transporte y Tránsito INTRA, peticionando la entrega de las tarjetas de operación por violación al debido proceso producto de la suspensión irregular del servicio público de transporte por parte de esta, en tal litigio que llego hasta la etapa de revisión, la Corte manifestó que en tal caso "sí hubo violación al derecho al debido proceso y las irregularidades anotadas obligan a la Corte a remitir copia del expediente a la Contraloría General de la República y a la Procuraduría General, para lo de su competencia". CConst, T-199/2006, C. Gaviria.

26 El artículo 22 dice así: "El artículo 135 de la Ley 769 de 2002, quedará así:

Artículo 135. Procedimiento. Ante la comisión de una contravención, la autoridad de tránsito debe seguir el procedimiento siguiente para imponer el comparendo:

Ordenará detener la marcha del vehículo y le extenderá al conductor la orden de comparendo en la que ordenará al Infractor presentarse ante la autoridad de tránsito competente dentro de los cinco (5) días hábiles siguientes. Al conductor se le entregará copia de la orden de comparendo. 
artículo $22^{26}$ de la Ley 1383 de 2010 "por la cual se reforma la Ley 769 de 2002 y se dictan otras disposiciones", el accionante pretendía que dicho artículo fuera retirado del ordenamiento jurídico en virtud de que este establecía la notificación o envío por correo la copia del comparendo al propietario del vehículo, a la empresa a la cual se encuentra vinculado y a la Superintendencia de Puertos y Transporte, como el único procedimiento válido para su efectiva comunicación, con lo cual, en todo caso, argumentaba el accionante, no se garantiza una verdadera oposición a la mencionada orden formal de notificación y, por ende, tampoco se materializa el derecho de contradicción. El asunto fue resuelto por la Corte en una encomiable disertación donde manifiesta que la notificación por correo dentro de la órbita de poder de la administración pública y en concreto del sector de transporte terrestre automotor, materializa una parte del principio de publicidad como parte del derecho constitucional al debido proceso dentro de las exigencias del debido proceso administrativo, asimilando que tal notificación surte efectos a partir de que el interesado y/o destinatario recibe la decisión que se pretende comunicar. Con este planteamiento la Corte siempre congruente con sus posiciones, busca que las formas y procedimientos utilizados por el legislador en su libre configuración y potestad legislativa, ${ }^{27}$ se adecuen a las exigencias constitucionales que hemos comentado en el punto segundo del presente artículo de reflexión crítica.

A modo de conclusión, los aspectos específicos tratados reflejan que independientemente de la dinámica legislativa inmersa, la Corte y el Consejo

\section{Para el servicio además se enviará por correo dentro de los tres (3) días hábiles siguientes copia del comparendo al propietario del vehiculo, a la empresa a la cual se encuentra vinculado y a la Superintendencia de Puertos y Transporte para lo de su competencia.}

La orden de comparendo deberá estar firmada por el conductor, siempre y cuando ello sea posible. Si el conductor se negara a firmar o a presentar la licencia, firmará por él un testigo, el cual deberá identificarse plenamente con el número de su cédula de ciudadanía o pasaporte, dirección de domicilio y teléfono, si lo tuviere.

No obstante lo anterior, las autoridades competentes podrán contratar el servicio de medios técnicos y tecnológicos que permitan evidenciar la comisión de infracciones o contravenciones, el vehículo, la fecha, el lugar y la hora. En tal caso se enviará por correo dentro de los tres (3) días hábiles siguientes la infracción y sus soportes al propietario, quien estará obligado al pago de la multa. Para el servicio público además se enviará por correo dentro de este mismo término copia del comparendo y sus soportes a la empresa a la cual se encuentre vinculado y a la Superintendencia de Puertos y Transporte para lo de su competencia.

El Ministerio de Transporte determinará las características técnicas del formulario de comparendo único nacional, así como su sistema de reparto. En éste se indicará al conductor que tendrá derecho a nombrar un apoderado si así lo desea y que en la audiencia, para la que se le cite, se decretarán o practicarán las pruebas que solicite. El comparendo deberá además proveer el espacio para consignar la dirección del inculpado o del testigo que lo haya suscrito por éste.

Parágrafo $1^{\circ}$. La autoridad de tránsito entregará al funcionario competente o a la entidad que aquella encargue para su recaudo, dentro de las doce (12) horas siguientes, la copia de la orden de comparendo, so pena de incurrir en causal de mala conducta.

Cuando se trate de agentes de policía de carreteras, la entrega de esta copia se hará por conducto del comandante de la ruta o del comandante director del servicio.

Parágrafo $2^{\circ}$. Los organismos de tránsito podrán suscribir contratos o convenios con entes públicos o privados con el fin de dar aplicación a los principios de celeridad y eficiencia en el cobro de las multas". Negrita propia de la sentencia.

27 En el mencionado fallo de constitucionalidad, la Corte hizo dos interesantes pronunciamientos sobre la configuración de la potestad sancionatoria de la administración, por parte del legislador, en uno de ellos adujo que: “(h)a considerado la Corte como legitimó que el legislador, en el ejercicio de su función de hacer las leyes, diseñe un sistema de notificación de los actos administrativos que resulte compatible con los progresos tecnológicos que tienen lugar en el campo de las telecomunicaciones, lo que a su juicio ocurre con los servicios de correo. Por eso, no ha dudado en considerar constitucionalmente admisible la notificación por correo, sobre la base de que la misma asegura, tanto el conocimiento real del acto administrativo a comunicar, como la posibilidad cierta del ejercicio del derecho de defensa". C - 980 de 1 de diciembre de 2010. En otro pronunciamiento la Corte retoma este argumento, pero con la idea más precisa de imponer límites a esta facultad del legislador de regular la potestad sancionatoria de la administración bajo el respeto al derecho constitucional del debido proceso recogido en el artículo 29 de la Carta política, en dicho pronunciamiento la Corte sostuvo que "En síntesis, la Corte ha insistido en reiterada jurisprudencia que el Legislador tiene una amplia facultad de regulación en materia de tránsito terrestre, y que por tanto puede legítimamente imponer limitaciones, restricciones y sanciones a los usuarios del sistema de tránsito terrestre que cometan infracciones, siempre y cuando estas limitaciones y sanciones cumplan con una finalidad constitucional, sean razonables y proporcionales, y respeten el debido proceso. Así mismo, ha dejado sentado esta Corporación que en materia de procedimientos y procesos administrativos de tránsito, le asiste al Legislador una amplia potestad de regulación, con el respeto de todas las garantías que le son inherentes al derecho fundamental del debido proceso consagrado en el artículo 29 Superior”. (CConst, C-089/2011, L. Vargas). 
buscan a través de su jurisprudencia que los aspectos específicos de la potestad sancionatoria de la administración en materia de transporte terrestre automotor, se ciña a los postulados jurisprudenciales pero sobre todo a los principios y normas constitucionales y legales que propugnan la defensa del derecho constitucional al debido proceso. Bien se trate de normas y figuras que se adecuan a las realidades tecnológicas 0 fácticas actuales, 0 bien sea una figura cualquiera, toda debe propender por una teleología que busca el equilibrio entre la sanción que promueve los fines inherentes al Estado Social de Derecho y los derechos constitucionales de los afectados que reclaman un debido proceso y un trato justo por parte del Estado.

\section{CONCLUSIONES}

Revisadas las fuentes mencionadas y analizado la regulación jurisprudencial de la potestad sancionatoria de la administración en materia de transporte terrestre automotor, se concluye:

El transporte terrestre automotor es aquella actividad de tipo transportador definida como aquel conjunto organizado de operaciones que realiza el traslado de personas o cosas, bien sea de forma separada o de forma conjunta de un lugar a otro bajo la regulación y autorización que fija el ordenamiento jurídico. Es un error frecuente dentro de los estudios y casos judiciales asimilar el concepto transporte terrestre automotor con el concepto tránsito terrestre automotor; este último regula la circulación de agentes que componen la movilidad en vías públicas 0 privadas.

El transporte terrestre automotor es un servicio público de carácter esencial que debe asegurar el interés general sobre el particular en su prestación, y además, se constituye como un instrumento al cual le es inherente el cumplimiento de las finalidades del Estado social de derecho recogido en la Carta política de 1991. Al ser caracterizado como servicio público esencial el Estado se reserva las funciones estatales de vigilancia, regulación y control que recae sobre aquel.
Para asegurar el interés general en la prestación del servicio del transporte terrestre automotor en el Estado colombiano, la administración pública cuenta con la potestad sancionatoria, que es una función estatal de control que le permite imponer sanciones como una prerrogativa de la potestad de mando que tiene como cometido reprimir las acciones u omisiones antijurídicas para poder asegurar el cumplimiento tanto de las decisiones de la autoridad pública como de los cometidos y principios impuestos por la Constitución y el restante ordenamiento jurídico. Con lo cual se busca la coexistencia y equilibrio entre la propiedad privada y la función social que le es inherente.

Conforme a las leyes 105 de 30 de diciembre de 1993 y 336 de 20 de diciembre de 1996, la administración pública podrá ejercer la potestad sancionatoria como función de control en materia de transporte terrestre automotor a través de un procedimiento con jurisdicción y competencia funcional que será llevado a cabo por los alcaldes y la Superintendencia de Puertos y Transporte, pudiendo imponer a los operadores y empresas de transporte sanciones que van desde las amonestaciones, las multas, hasta la suspensión o cancelación de la licencia, registros, habilitaciones o permisos de operación.

Tanto la Corte como el Consejo han coincidido en la construcción jurisprudencial de la caracterización de la potestad sancionatoria de la administración en materia de transporte terrestre automotor, estableciendo límites a la misma derivados del derecho constitucional al debido proceso. En contraposición a este ejercicio por parte de las altas cortes, el desarrollo y contribución de la temática por parte del sector académico ha sido bastante escaso en Colombia.

El Consejo y la Corte, pero especialmente esta última, se han destacado por limitar la potestad sancionatoria de la administración, especialmente en el empeño de asegurar que esta respete los postulados y directrices contenidas en el artículo 29 de la Constitución de 1991, que regula el derecho constitucional fundamental al debido proceso. 
El despliegue de actuaciones por parte de las autoridades públicas en ejercicio de la potestad sancionatoria en el sector del transporte terrestre automotor, debe respetar los límites y contenidos reseñados en la caracterización del derecho constitucional fundamental al debido proceso, que por vía jurisprudencial se han identificado como: el derecho a la jurisdicción, al derecho a un juez natural, al derecho a la defensa, al derecho a un proceso público, al derecho a la independencia del juez y por último al derecho a la imparcialidad del juez o funcionario. Además estos límites y sus componentes deben ser recogidos en la futura construcción y/o modificación de la legislación que regula la materia.

Entre los aspectos específicos más importantes que ha tratado la jurisprudencia de la Corte y el Consejo, están los referentes a los cambios en las autorizaciones de rutas, horarios, niveles de servicio y fijación de la capacidad transportadora por un lado, y por otro el envío de comparendos por correo. En la regulación y actuaciones administrativas de dichos temas se determinó que cualquier acción tendiente a limitar tales aspectos se debe ceñir a los principios y normas constitucionales y legales que propugnan la defensa del derecho constitucional al debido proceso. Así, en el caso de las tarjetas de operación las autoridades públicas no podrán revocar dichos permisos sin que medie el consentimiento del afectado, o ser demandadas ante la jurisdicción de lo contencioso administrativo.

Tanto la Corte como el Consejo han tratado con más insistencia el tema de tránsito terrestre automotor que el de transporte terrestre automotor, sobre este último son específicos y muy escasos los tópicos tratados, requiriendo un mayor pronunciamiento en áreas diferentes a las notificaciones de las sanciones, y a las cancelaciones de las tarjetas de operación, permitiendo de esta manera mayores garantías en los servicios prestados por los operadores de servicios de transporte terrestre automotor.

\section{REFERENCIAS BIBLIOGRAFICAS}

- Atehortúa, C. (2006).Servicios públicos domiciliarios, proveedores y régimen de controles. Bogotá D.C. Universidad Externado de Colombia.

- Benlloch, G. (1998). El Principio de non bis in idem en las relaciones entre el Derecho penal y el Derecho disciplinario. Revista del Poder Judicial (51) págs. 322 - 324.

- De la Rosa Cortina, J. (2003). Relaciones entre derecho penal y derecho administrativo sancionador. En especial, el principio Non Bis In Idem, Revista del Ministerio Fiscal (11), Ministerio de Justicia, Madrid.

- Nieto, A. (2005). Derecho administrativo sancionador, 4 edición. Madrid. Editorial Tecnos.

- Ossa, J. (2000). Derecho administrativo sancionador, Una aproximación dogmática, 2 edición. Bogotá. editorial Legis.

- Parada, J. (1972). El poder sancionador de la administración y la crisis del sistema judicial penal. Revista de administración pública (67).

- Santofimio, J. (2003) Tratado de derecho administrativo, acto administrativo: procedimiento, eficacia y validez, 4 edición. Bogotá, D.C. Universidad Externado de Colombia.

\section{Referencias Normativas}

- C.N

- L 105/1993.

- L 336/1996.

- L 769/2002.

- L 1383/2010.

\section{Referencias Jurisprudenciales}

- Consejo de Estado

- CE1, 14 May. 1998, r2126, L. Rodríguez.

- CE1, 3 Jun. 1999, r5200, E. Ariza.

- CE1, 19 0ct. 2000, r5964, G. Mendoza.

- CE1, 21 Sept. 2001, r6792, M. Urueta.

- CE1, 7 Mar.2002, r7293, M. Urueta.

- CE1, 6 Sept. 2002, r6982, M. Urueta.

- CE1, 24 Jul. 2003, r8365, M. Urueta.

- CE4, 25 Ago. 2005, M. Ortiz.

- CE1, 20 Oct. 2005, r7826, R. Ostau de Lafont Pianeta. 
- $\quad$ CE4, 10 May. 2007, M. Ortiz.

- CE1, 3 Jul. 2008, r209-01, R. Ostau de Lafont Pianeta

- CE3, 2 Abr. 2009, M. Velilla.

- CE4, 28 May. 2009, M. Sanz.

- CE4, 24 Sept. 2009, M. Sanz.

- CE1, 12 Nov. 2009, R. Ostau de Lafont Pianeta.

- CE1, 26 Nov.2009, M. Rojas

- CE3, 4 Feb. 2010, M. Velilla

- CE1, 6 May. 2010. R. Ostau de Lafont Pianeta.

- CE1, 10 Jun. 2010, M. Rojas.
- CE1, 7 0ct. 2010, M. García.

- CE1, 29 Nov. 2010, R. Ostau De Lafont Pianeta

- CE1, 18 Agosto 2011, R. Ostau De Lafont Pianeta

Corte Constitucional

- CConst, T-976/1999, F. Morón.

- CConst, T-786 /2000, Barrera, A.

- CConst, T-214 /2006, Monroy, M.

- CConst, T-199/2006, Gaviria, C.

- CConst, C-980 /2010, Mendoza, G.

- CConst, C-089/2011, Vargas, L. 